\title{
Heat Transfer Boundary Conditions in the RELAP5-3D Code
}

\author{
ICONE 16
}

Richard A. Riemke

Cliff B. Davis

Richard R. Schultz

The INL is a

U.S. Department of Energy

National Laboratory

operated by

Battelle Energy Alliance

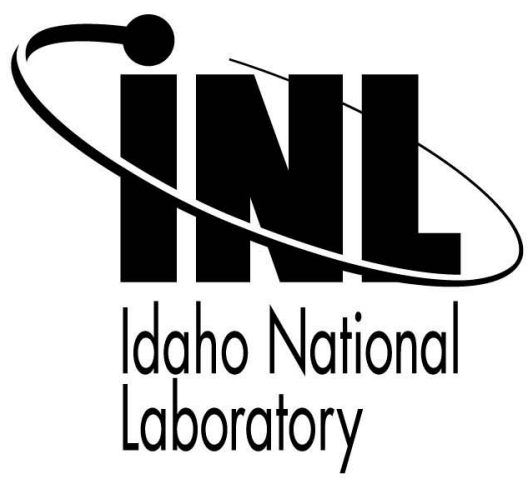

This is a preprint of a paper intended for publication in a journal or proceedings. Since changes may be made before publication, this preprint should not be cited or reproduced without permission of the author. This document was prepared as an account of work sponsored by an agency of the United States Government. Neither the United States Government nor any agency thereof, or any of their employees, makes any warranty, expressed or implied, or assumes any legal liability or responsibility for any third party's use, or the results of such use, of any information, apparatus, product or process disclosed in this report, or represents that its use by such third party would not infringe privately owned rights. The views expressed in this paper are not necessarily those of the United States Government or the sponsoring agency. 


\title{
HEAT TRANSFER BOUNDARY CONDITIONS IN THE RELAP5-3D CODE
}

\author{
Richard A. Riemke \\ Idaho National Laboratory, Idaho Falls, Idaho \\ 83415-3890, USA \\ Phone: 208-526-0697 \\ Fax: 208-526-0528 \\ Email: Richard.Riemke@inl.gov
}

\author{
Cliff B. Davis \\ Idaho National Laboratory, Idaho Falls, Idaho \\ 83415-3890, USA \\ Phone: 208-526-9470 \\ Fax: 208-526-0528 \\ Email: Cliff.Davis@inl.gov
}

\author{
Richard R. Schultz \\ Idaho National Laboratory, Idaho Falls, Idaho \\ 83415-3890, USA \\ Phone: 208-526-9508 \\ Fax: 208-526-0528 \\ Email: Richard.Schultz@inl.gov
}

\begin{abstract}
The heat transfer boundary conditions used in the RELAP5-3D computer program have evolved over the years. Currently, RELAP5-3D has the following options for the heat transfer boundary conditions: (a) heat transfer correlation package option, (b) non-convective option (from radiation/conduction enclosure model or symmetry/insulated conditions), and (c) other options (setting the surface temperature to a volume fraction averaged fluid temperature of the boundary volume, obtaining the surface temperature from a control variable, obtaining the surface temperature from a timedependent general table, obtaining the heat flux from a timedependent general table, or obtaining heat transfer coefficients from either a time- or temperature-dependent general table). These options will be discussed, including the more recent ones.
\end{abstract}

\section{INTRODUCTION}

The RELAP5 series of codes has been developed at the Idaho National Laboratory for over 25 years under sponsorship of the U. S. Department of Energy, the U. S. Nuclear Regulatory Commission, members of the International Code
Assessment and Applications Program, members of the Code Applications and Maintenance Program, and members of the International RELAP5 Users Group. Specific world-wide applications of the code have included simulations of transients of light water reactor systems such as loss of coolant, anticipated transients without scram, and operational transients such as loss of feedwater, loss of offsite power, station blackout, and turbine trip. RELAP5-3D (Ref. 1), the latest in the series of RELAP5 codes, extends the applicability of earlier versions to include an integrated multidimensional thermalhydraulic/neutronic capability. In addition to calculating the behavior of a reactor coolant system during a transient, it can be used for simulation of a wide variety of hydraulic and thermal transients in both nuclear and nonnuclear systems involving mixtures of vapor, liquid, noncondensable gases, and nonvolatile solute. The 3D capability in RELAP5-3D includes 3D hydrodynamics and 3D neutron kinetics [the 3D neutronics is based on the NESTLE code (Ref. 2)]. RELAP5-3D was recently modified to include all the ATHENA (Ref. 3) features and models that were previously only available in the ATHENA configuration. The ATHENA features and models are currently used primarily in Generation IV reactor applications, GNEP reactor applications, space reactor applications, and nuclear fusion applications. 
RELAP5-3D is also used in a SCDAP/RELAP5-3D (Ref. 4) configuration that is designed to calculate for severe accident situations the overall reactor coolant system thermalhydraulic response, core damage progression, and reactor vessel heatup and damage. RELAP5-3D (also true of SCDAP/RELAP5-3D) is also used in an integrated code system configuration consisting of RELAP5-3D and other codes such as FLUENT, CFX, and CONTAIN. The coupling of the codes in this configuration is coordinated using an executive program (Ref. 5) in concert with the Parallel Virtual Machine (PVM) message passing software. The coupling can be done explicitly or semi-implicitly. For example, the FLUENT/RELAP5-3D (Ref. 6) coupling configuration is designed to perform detailed 3D analyses using FLUENT's capability while the boundary conditions required by the FLUENT calculation are provided by the balance-of-system model created using RELAP5-3D. The FLUENT/RELAP5-3D coupling configuration is currently used primarily in Generation IV reactor applications. RELAP5-3D is also used for the thermal-hydraulic module in the real-time nuclear plant simulation code RELAP5-R/T (Refs. $7,8,9$ ), which is used in training simulators at nuclear power plants around the world. There is also a visualization system for the various RELAP5-3D configurations, which is called the RELAP5-3D Graphical User Interface (RGUI) (Ref. 10).

This paper provides an overview of the heat transfer models in RELAP5-3D and then discusses the heat transfer boundary conditions used in the RELAP5-3D computer program. Currently, RELAP5-3D has the following options for the heat transfer boundary conditions: heat transfer correlation package option, non-convective option, and other options. These options will be discussed, including the more recent ones.

\section{HEAT TRANSFER MODELS}

Heat structures provided in RELAP5-3D permit calculation of the heat transferred across solid boundaries of hydrodynamic volumes. Modeling capabilities of heat structures are general and include fuel pins or plates with nuclear or electrical heating, heat transfer across steam generator tubes, and heat transfer from pipe and vessel walls. Temperatures and heat transfer rates are computed from the one-dimensional form of the transient heat conduction equation for non-reflood and from the two-dimensional form of the transient heat conduction equation for reflood.

For one-dimensional heat conduction, heat structures are represented using rectangular, cylindrical, and spherical geometry. For two-dimensional heat conduction, heat structures are represented using only rectangular and cylindrical geometry. Temperature-dependent and spacedependent thermal conductivities and volumetric heat capacities are provided in tabular or functional form either from built-in or user-supplied data. This is discussed further in the RELAP5-3D manual (Ref. 1) and in a recent ICAPP '06 paper (Ref. 11).

Finite differences are used to advance the heat conduction solutions. Each mesh interval may contain a different mesh spacing, a different material, or both. The spatial dependence of the internal heat source may vary over each mesh interval. The time-dependence of the heat source can be obtained from reactor kinetics, one of several tables of power versus time, or a control system variable.

Boundary condition input to RELAP5-3D specifies the type of boundary condition, the possible attachment of a heat structure surface to a hydrodynamic volume, and the relating of the one-dimensional or two-dimensional heat conduction solution to the actual three-dimensional nature of the structure. Each of the two surfaces of a heat structure may use any of the boundary conditions and may be connected to a hydrodynamic volume, but only one hydrodynamic volume may connect to a heat structure surface. When a heat structure is connected to a hydrodynamic volume, heat transferred from or to the heat structure is added to or subtracted from the internal energy content of the hydrodynamic volume.

\section{HEAT TRANSFER CORRELATION PACKAGE OPTION}

The heat transfer correlation package option can be used for heat structure surfaces connected to hydrodynamic volumes. The heat transfer correlation package contains correlations for turbulent forced convection, laminar forced convection, natural convection, subcooled nucleate boiling, saturated nucleate boiling, subcooled transition boiling, saturated transition boiling, subcooled film boiling (conduction, convection, radiation), and saturated film boiling (conduction, convection, radiation) heat transfer from the wall to the fluid. The heat transfer correlation package also contains correlations for critical heat flux (CHF). The heat transfer correlation package also contains correlations for turbulent forced convection, laminar forced convection, natural convection, and condensation (inclined surface, horizontal surface, noncondensables) heat transfer from the fluid to the wall.

A boiling curve is used in RELAP5-3D to govern the selection of the heat transfer correlations for heat transfer from the wall to the fluid. Much of the RELAP5-3D boiling curve logic is based on the value of the heat structure surface temperature. If noncondensable gas is present, there is a window region when the heat structure surface temperature is too small for boiling and too high for condensation. This occurs when the heat structure surface temperature is less than the saturation temperature based on total pressure but greater than the saturation temperature based on vapor partial pressure; convection heat transfer is used for this case. 
The heat transfer correlation package in RELAP5-3D uses heat transfer correlations that based on fully developed steadystate flow, where entrance length effects are not considered except for the calculation of CHF.

An important factor that affects the magnitude of heat transfer coefficients, besides obvious parameters such as velocity, is the flow field or hydraulic geometry surrounding the surface. The flow field next to the wall influences the velocity profile and turbulence. The two basic types of flow fields are internal and external.

For an internal flow field, typical hardware are pipes (horizontal, vertical, helical), parallel plates (horizontal, vertical), annuli (horizontal, vertical; inner wall heated, outer wall heated), and spheres (horizontal, vertical). For an external flow field, typical hardware are single tube (horizontal, vertical; with crossflow, without crossflow), single plate (horizontal, vertical; heated, cooled), tube bundle (horizontal, vertical, helical; square pitch, staggered pitch; with crossflow, without crossflow), spheres (horizontal, vertical). Pipes can be any shape, but RELAP5-3D has correlations for only circular pipes. Parallel plates are a special case of annuli; i.e., in the limit as the annuli inner radius gets large, the flow field is the same as flow between parallel plates. RELAP5-3D is capable of solving the heat conduction solution for spheres, but no heat transfer correlations specifically for spheres are currently in the code.

Coding has been implemented in RELAP5-3D for some of the flow fields [standard correlations for vertical and horizontal pipes, vertical parallel plates (ORNL ANS geometry), vertical bundle with in-line rods (parallel-flow and crossflow), vertical annuli with aluminum walls heated and downflow (SRL geometry), horizontal plate above fluid, horizontal bundle with in-line rods (parallel-flow and crossflow)]. Alternate geometry and/or correlations are also available [swirl tubes, optional condensation correlation in the presence of noncondensables in large tanks, several correlations used to support the analysis of advanced reactors cooled by supercritical fluids (including light water, helium, and carbon dioxide), convective heat transfer correlations for liquid metals for non-bundles and vertical bundles (with and without crossflow)]. For other flow fields for which there are no special correlations implemented in RELAP5-3D, these are associated and defaulted to a similar implemented correlation. In the future, it is planned to implement correlations for these other flow fields.

\section{NON-CONVECTIVE OPTION}

The non-convective option is used for the
radiation/conduction enclosure model and for
symmetry/insulated conditions.

The radiation/conduction enclosure model is comprised of two parts, the radiation enclosure model and the conduction model. The radiation enclosure model is used to compute the radiation exchange between surfaces. The surfaces that have a line-of-sight or a reflection path through which they can communicate with each other are in the same enclosure. The computational method is a lumped-system approximation for gray diffuse surfaces contained in an enclosure. In the radiation enclosure model, an emissivity and a reflectivity are used to characterize the thermal radiation connection between heat structures. The method assumes the fluid in the enclosure neither emits nor absorbs radiant thermal energy; reflectance from a surface is neither a function of incident nor reflected direction nor of radiation frequency; and temperature, reflectance, and radiosity are constant over each surface. The conduction enclosure model is an adaptation of the radiation enclosure model. The model can be used to simulate multidimensional heat conduction in a lumped parameter fashion. As is the case with the radiation enclosure model, the conduction enclosure model permits thermal 'connections' between an arbitrary number of heat structures. The only difference is the nature of the connection. In the conduction enclosure model, a gap conductance is used to characterize the thermal conduction connection between heat structures. This represents the ability to transfer heat via physical contact between heat structure surfaces.

The symmetry/insulated boundary condition specifies no heat transfer at the surface, that is a zero temperature gradient at the surface. This condition should be used in cylindrical or spherical coordinates when the radius of the left-most mesh point is zero, though the numerical techniques impose the condition regardless of the boundary condition specified. If a rectangular geometry is modeled with both surfaces attached to the same hydrodynamic volume, with the same boundary conditions, and having symmetry about the structure midpoint, storage space and computer time can be saved by describing only half of the structure. The symmetry boundary condition is then used at one of the surfaces, and the heat surface area is doubled. This boundary condition can also be used when a surface is very well insulated.

\section{OTHER OPTIONS}

The other boundary condition options that can be selected are as follows: setting the surface temperature to a volume fraction averaged fluid temperature of the boundary volume, obtaining the surface temperature from a control variable, obtaining the surface temperature from a time-dependent general table, obtaining the heat flux from a time-dependent general table, or obtaining heat transfer coefficients from either a time- or temperature-dependent general table. For the last option, the associated sink temperature can be a volume fraction averaged fluid temperature of a boundary volume, or it can be obtained from a time-dependent general table, or it can 
be obtained from a control variable, or it can be set to zero. These options are generally used to support various efforts to analyze experimental data and do not contain all the physics present in the boundary condition options that use the heat transfer correlations.

A new boundary condition option that can be selected is the alternate heat structure - fluid coupling model. This model increases the accuracy of the coupled solution of energy equations for the fluid and heat structures with vapor/gas coolants. This option is applicable when fluid temperature differences (between the inlet of the volume and the outlet of the volume) are not small for situations in which the fluid velocity is low or the heat capacity of the fluid is low (e.g., for vapor/gas fluids). The usual modeling approach is to add more volumes for a spatially converged solution. The purpose of the alternate heat structure - fluid coupling model is to increase the accuracy of the solution so that fewer computational volumes are needed. The method used for this alternate option (known as the 'exponential approach' method) assumes the average fluid temperature in the volume is a linear average of the inlet temperature and the outlet temperature.

The two-dimensional heat conduction model is in the process of being improved. Phase 1 of the improvements has been recently completed. This improvement was to separate the two-dimensional heat conduction model from the reflood model so that the two-dimensional heat conduction model could be used independently of the reflood model. Phase 2 of the planned improvements will be to allow the top and bottom ends of a heat structure geometry using the two-dimensional heat conduction model to be included in the radiation/conduction enclosure model. Phase 3 of the planned improvements will include allowing the heat transfer correlation package option to be used on the top and bottom surfaces of a heat structure geometry when using the twodimensional heat conduction model.

\section{CONCLUSIONS}

This paper has discussed the heat transfer boundary conditions used in the RELAP5-3D computer program. Currently, RELAP5-3D has the following options for the heat transfer boundary conditions: heat transfer correlation package option, non-convective option, and other options. These options were discussed, including the more recent ones.

\section{ACKNOWLEDGMENTS}

This work was funded through the DOE under DOE/NE Idaho Operations Office Contract No. DE-AC07-05ID14517.

\section{REFERENCES}

1. The RELAP5-3D Code Development Team, 2005, "RELAP5-3D Code Manual," INEEL-EXT-98-00834, Revision 2.4, June, http://www.inel.gov/relap5/r5manuals.htm.

2. Turinsky, P., et al., 1994, "NESTLE: A Few-Group Neutron Diffusion Equation Solver Utilizing the Nodal Expansion Method for Eigenvalue, Adjoint, Fixed-Source Steady State and Transient Problems," EGG-NRE-11406, June.

3. Johnsen, G., C. Davis, and P. Bayless, 2004, ATHENA-3D for Generation IV Reactor Analysis, BE-2004, American Nuclear Society Winter Meeting, Washington DC, USA, November 14-18, http://www.inel.gov/relap5/athena/athena.htm.

4. The SCDAP/RELAP5-3D Development Team, 2003, "SCDAP/RELAP5-3D Code Manual," INEEL-EXT02-00589, Revision 2.2, October, http://www.inel.gov/relap5/scdap/scdap.htm.

5. Weaver, W., E. Tomlinson, and D. Aumiller, 2001, “A PVM Executive Program for Use with RELAP5-3D," 2001 RELAP5 International Users Seminar, Sun Valley, ID, USA, September 5-7, http://www.inel.gov/relap5/rius/sunvalley/weaver.pdf.

6. Schultz, R. and W. Weaver, 2003, "Using the RELAP5-3D Advanced Systems Analysis Code with Commercial and Advanced CFD Software," ICONE11, $11^{\text {th }}$ International Conference on Nuclear Engineering, Tokyo, Japan, April 20-23.

7. Williams, K., 2001, "Full-Scope Simulators Running Real-time RELAP5-R/T," 2001 RELAP5 International Users Seminar, Sun Valley, ID, USA, September 5-7, http://www.inel.gov/relap5/rius/sunvalley/williams.pdf

8. Hiltbrand, D. and K. Williams, 2001, "Utilization of a RELAP5 RCS and Secondary Plant Model in a Nuclear Power Plant Training Simulator," 2001 RELAP5 International Users Seminar, Sun Valley, ID, USA, September 5-7, http://www.inel.gov/relap5/rius/sunvalley/hiltbrandwilliams.pdf.

9. Judd, J., et al., 1996, "High-Fidelity, Real-Time Simulation with RELAP5/NESTLE," American Nuclear Society Winter Meeting, Washington, DC, USA, November 10-14.

10. Mesina, G., 2004, Visualization of RELAP5-3D Best Estimate Code, BE-2004, American Nuclear Society 
Winter Meeting, Washington, DC., USA, November 14-18,

http://www.inel.gov/relap5/products.htm.

11. Riemke, R., P. Bayless, and S. Modro, 2006, "Recent Improvements to RELAP5-3D Code,' ICAPP '06, 2006 International Congress on Advances in Nuclear Power Plants, Reno, NV, USA, June 4-8. 